Part of Journal of Research of the National Bureau of Standards, Volume 22, April 1939

\title{
PREPARATION AND PROPERTIES OF $\beta$-d-2-DESOXYGALACTOSE
}

\author{
By Horace S. Isbell and William W. Pigman
}

\section{ABSTRACT}

The preparation of crystalline $\beta$ - $d$-2-desoxygalactose, $\mathrm{C}_{6} \mathrm{H}_{12} \mathrm{O}_{5}$, is described and its properties reported. It melts at $121^{\circ} \mathrm{C}$ and gives the pine-splinter and digitoxin reactions for desoxy sugars. With Fehling's solution the reducing power is about that of dextrose, but with less alkaline reagents like Benedict's solution its reducing power is less and varies widely with the boiling time. In 4percent aqueous solution buffered with $0.001 \mathrm{~N}$ potassium acid phthalate, $\beta-d-2-$ desoxygalactose gives $[\alpha]_{D}^{20}=+41$ initially, decreases in 5 minutes to a minimum of +37 , and increases thereafter to an equilibrium value of +60.5 . The heat of activation for the rapid mutarotation reaction is less than that of the slow mutarotation reaction. The proportions of the constituents responsible for the rapid reaction change with temperature more than the proportions of those which cause the slow reaction. The mutarotation of the new sugar shows that it establishes an equilibrium with an alpha pyranose modification and a labile substance.

\section{CONTENTS}

I. Introduction and discussion . $\ldots \ldots \ldots$

II. Experimental procedure

1. Preparation of $\beta-\bar{d}-2$-desoxygalactose

2. Properties of $\beta$ - $d$-2-desoxygalactose $\ldots \ldots \ldots \ldots$

III. References_........ 402

\section{INTRODUCTION AND DISCUSSION}

Our previous investigations $[1,2,3,4]^{1}$ have shown that the configurations of the first five carbon atoms in the reducing sugars determine in large measure the position of the equilibrium which is established when the sugar is dissolved in water. The configuration of the carbon adjacent to the reducing group influences in marked degree the properties of the sugar and the relative proportions of the alpha and beta isomers. It is therefore of interest to investigate the 2-desoxy sugars in which the second carbon is not asymmetric.

In 1931 Levene and Tipson [5] reported the preparation of 2desoxygalactose. This substance appeared to be suitable for our investigation because it is closely related to $d$-galactose, a sugar which had been carefully studied. We had on hand a quantity of galactal [6] from which we prepared desoxygalactose by the method of Bergmann and Schotte [7]. The sugar was obtained as described on page 398 by the following reactions:

\footnotetext{
${ }^{1}$ Figures in brackets indicate the literature references at the end of this paper.
} 


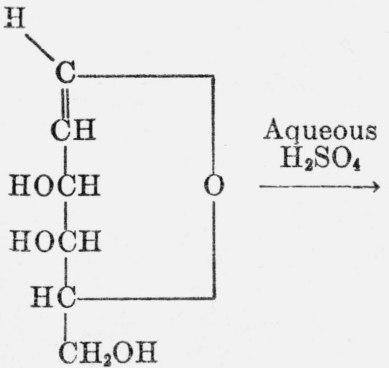

Galactal

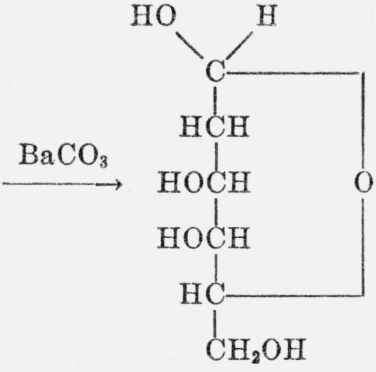

$\beta-d$-2-Desoxygalactose

Desoxygalactose, like galactose and other sugars which have opposite configurations for the groups on carbons 4 and 5 , is particularly suitable for studying the interconversion of the pyranose and furanose modifications [8].

Different configurations for carbons 4 and 5 cause large differences in the optical rotations of the pyranose and furanose modifications. If carbons 4 and 5 are of different configuration, small changes in the proportions of the pyranose and furanose modifications can be detected by optical rotation measurements. The mutarotations of sugars which differ in the configurations of carbons 4 and 5 usually exhibit maximum or minimum values. When desoxygalactose is dissolved in water the optical rotation decreases to a minimum and then rises slowly until a constant value is reached. The changes reveal that a more levorotatory modification is formed from the parent sugar at a relatively rapid rate, while simultaneously, a more dextrorotatory substance is formed at a slower rate. More than three substances may be involved in the equilibrium state but the optical rotations do not suffice to prove the presence or absence of more than three substances. The heat of activation for the rapid reaction is less than that of the slow reaction. Presumably the rapid change in optical rotation is caused by a reaction analogous to the rapid mutarotation reaction of galactose which we have shown [8] to consist primarily in an alteration in ring structure. The slower mutarotation appears to be analogous to the mutarotation of glucose and other alpha and beta pyranose interconversions. If it be assumed that the sugar is a pyranose (an assumption which is probably correct), the crystalline sugar is the less dextrorotatory member of the alpha-beta pair, and since the oxygen ring lies to the right the sugar is classified as the beta modification. The proportions of the various modifications in the equilibrium solution change with temperature so that an alteration in temperature results in a "thermal mutarotation." The composition of the equilibrium solution and the rates of reaction are being investigated further in this laboratory and will be treated more fully in a subsequent publication.

\section{EXPERIMEN'TAL PROCEDURE}

\section{PREPARATION OF $\beta$ - $d$-2-DESOXYGALACTOSE}

Fifty grams of pure crystalline galactal was dissolved at $0^{\circ} \mathrm{C}$ in $700 \mathrm{ml}$ of 5-percent sulfuric acid. The solution was allowed to stand overnight at $0^{\circ} \mathrm{C}$. On the following day, $120 \mathrm{~g}$ of barium 
carbonate was added. The mixture was heated with mechanical stirring to $60^{\circ} \mathrm{C}$ and kept at this temperature during working hours for about 1 week. Additional barium carbonate was added from time to time so that in all about $200 \mathrm{~g}$ was added. The excess barium carbonate was separated on a filter and the filtrate was boiled down to a thick sirup, which was taken up in about $50 \mathrm{ml}$ of absolute ethyl alcohol. During the following night, crystallization occurred spontaneously. The crystals were separated and the mother liquor was evaporated in a desiccator over calcium chloride to give a second crop of crystals. The yield of crude desoxygalactose was $40 \mathrm{~g}$.

The crude sugar was dissolved in water and after the addition of a small quantity of decolorizing carbon it was evaporated in vacuo to a thick sirup, which was diluted with three volumes of methyl alcohol and seeded with crystals from the first preparation. The resulting crystals were collected on a filter and washed with methyl alcohol and dried at room temperature over calcium chloride.

\section{PROPERTIES OF $\beta$ - $d$-2-DESOXYGALACTOSE}

(a) Melting point. $-120^{\circ}$ to $121^{\circ} \mathrm{C}$.

(b) Analysis.-Calculated for $\mathrm{C}_{6} \mathrm{H}_{12} \mathrm{O}_{5}: \mathrm{C}, 43.90 ; \mathrm{H}, 7.37$. Found: $\mathrm{C}, 44.05 ; \mathrm{H}, 7.35$.

(c) Iodine titration.-During titration of the sugar by the method of Kline and Acree [9], $0.1683 \mathrm{~g}$ of the sugar consumed $21.74 \mathrm{ml}$ of $N / 10$ iodine solution; $\mathrm{C}_{6} \mathrm{H}_{12} \mathrm{O}_{5}$ requires $20.50 \mathrm{ml}$.

(d) Qualitative tests for desoxy sugars [10].-A pine shaving impregnated with a solution of the sugar and exposed to warm vapors of aqueous hydrochloric acid gives the dark green coloration characteristic of desoxy sugars.

A very dilute solution of the sugar dissolved in acetic acid containing ferric sulphate carefully poured over sulfuric acid containing ferric sulfate gives a violet ring which fades into reddish-brown in the lower part of the tube. This reaction, which is sometimes called the digitoxin reaction, appears to be characteristic of 2-desoxy sugars [10].

(e) Copper-reducing value.-By the Munson and Walker method [11] 60-mg samples of the sugar gave 131.4, 131.2, and $131.2 \mathrm{mg}$ of $\mathrm{Cu}_{2} \mathrm{O}$, and a $30-\mathrm{mg}$ sample of the sugar gave $66.3 \mathrm{mg}$ of $\mathrm{Cu}_{2} \mathrm{O}$. It requires $57.3 \mathrm{mg}$ of dextrose to give $131.2 \mathrm{~g}$ of $\mathrm{Cu}_{2} \mathrm{O}$ and $28.4 \mathrm{mg}$ of dextrose to give $66.3 \mathrm{mg}$ of $\mathrm{Cu}_{2} \mathrm{O}$. Consequently, the reducing-power factor for the larger sample of desoxygalactose equals 57.2/60, or 0.95 .

In copper solutions buffered with carbonates the sugar is oxidized very slowly and gives low reducing values unless the period of boiling is extended beyond the usual time. With Scales' method [12] for determining the cuprous oxide and using boiling periods of 6,10 , and 15 minutes, $20-\mathrm{mg}$ samples of the sugar give cuprous oxide equivalent to $8.67,13.57$, and $17.32 \mathrm{ml}$ of $0.04 \mathrm{~N}$ iodine, respectively, for $6-, 10-$, and 15-minute boiling periods. With a modified Scales method, using a 6-minute boiling period, it requires only $9.3 \mathrm{mg}$ of glucose to give cuprous oxide equivalent to $8.67 \mathrm{ml}$ of $0.4 \mathrm{~N}$ iodine. Hence by this method the relative reducing value of desoxygalactose equals $9.3 / 20$, or 0.46 . The original Scales method calls for a boiling period of only three minutes, at which time desoxygalactose has only begun to reduce the copper reagent. 
(f) Optical-rotation measurements.-The optical rotations as recorded in tables 1,2 , and 3 were measured in a 4-dm water-jacketed glass tube on a Bates saccharimeter. The equilibrium specific rotation was determined on separate samples at the concentration and temperature used in the mutarotation measurements. The velocity constants and equations representing the optical rotations were calculated by the method described by us on page 156 of reference [1]. The equations showing the specific rotations were obtained from the equations expressed in sugar degrees by multiplying the latter by the ratio of the equilibrium specific rotation to the equilibrium rotation as observed in sugar degrees.

The heats of activation were calculated by the Arrhenius equation, ${ }^{2}$ using mutarotation constants obtained from the measurements in aqueous solutions buffered with potassium acid phthalate. The value $(10,700)$ obtained for the more rapid reaction resembles the average $(13,200)$ previously found for the rapid mutarotations of galactose, talose, arabinose, and ribose, while the value $(15,650)$ obtained for the slow reaction resembles the average $(16,900)[1, p .165]$ previously found for the interconversion of the more common alpha and beta pyranose sugars. The activation constants correspond to a temperature coefficient ${ }^{3} k_{35} / k_{25}$ of 1.80 for the more rapid reaction and 2.35 for the slow reaction.

TABLE 1.-Mutarotation of $\beta-d-\mathbb{D}$-desoxygalactose at $20^{\circ} \mathrm{C}$

\begin{tabular}{|c|c|c|c|c|}
\hline Time & $\begin{array}{l}\text { Observed } \\
\text { reading }\end{array}$ & $m_{1} \times 10^{3}$ & Deviation & $m_{2} \times 10^{3}$ \\
\hline Minutes & ${ }^{\circ} \mathrm{S}$ & & & \\
\hline $\begin{array}{l}0 \\
2.13\end{array}$ & +17.54 & - & & \\
\hline 3. 33 & +17.40 & - - non & 4.12 & 95 \\
\hline 4. 62 & +17.21 & - & 2.84 & 110 \\
\hline 6. 24 & +17.42 & . & 1.80 & 115 \\
\hline 7. 17 & +17.80 & - & 1. 51 & 109 \\
\hline 7. 93 & +18.10 & - & 1. 29 & 107 \\
\hline 8. 69 & $\begin{array}{l}+18.39 \\
\end{array}$ & .......... & 1.08 & 106 \\
\hline $\begin{array}{r}9.58 \\
11.50\end{array}$ & $\begin{array}{l}+18.80 \\
+19.51\end{array}$ & 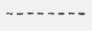 & 0.93 & 102 \\
\hline 13. 45 & $\begin{array}{r}1.03 \\
+20.33\end{array}$ & (n) & .36 & 104 \\
\hline 16.50 & +21.50 & & .17 & 104 \\
\hline 20.40 & +22.74 & & & \\
\hline 25.80 & +24.24 & 25.5 & -......... & -...... \\
\hline 30. 31 & +25.16 & 25.3 & - & -...... \\
\hline $\begin{array}{l}37.52 \\
45.38\end{array}$ & $\begin{array}{r}+26.29 \\
+26.99\end{array}$ & $\begin{array}{l}26.1 \\
25.5\end{array}$ & - n- & . \\
\hline 51.52 & +27.33 & 24.9 & - n & -...... \\
\hline 60.60 & +27.73 & 25.3 & - & -.... \\
\hline $23 \mathrm{hr}$. & +28.26 & - nen & - n...... & $-\ldots . .$. \\
\hline Average.-. & ........... & 25.4 & - & 106 \\
\hline
\end{tabular}

$2.3026 \log \frac{k_{1}}{k_{2}}=\frac{Q}{1.9864}\left(\frac{1}{T_{2}}-\frac{1}{T_{1}}\right)$

The heat of activation, $Q$, obtained from the mutarotation coefficient is an empirical constant.

${ }_{3} \log k_{35} / k_{25}=Q / 42,111$ 
TABLE 2.-Mutarotation of $\beta-d-2-$ desoxygalactose at $0.2^{\circ} \mathrm{C}$

\begin{tabular}{|c|c|c|c|c|}
\hline \multicolumn{5}{|c|}{$\begin{array}{c}4 \mathrm{~g} \text { in } 100 \mathrm{ml} \text { of } 0.001 \mathrm{~N} \text { potassium acid phthalate solution. } \\
\begin{aligned} \circ & S=-16.72 \times 10^{-.00359 t}+5.20 \times 10^{-.0278 t}+31.06 \\
{[\alpha]_{D}^{0.2} } & =-36.4 \times 10^{-.00359 t}+11.3 \times 10^{-.0278 t}+67.6 \\
{[\alpha]_{D}^{0.2} } & =+42.5 \text { initially, }+67.6 \text { at equilibrium. }\end{aligned}\end{array}$} \\
\hline Time & $\begin{array}{l}\text { Observed } \\
\text { reading }\end{array}$ & $m_{1} \times 10^{3}$ & Deviation & $m_{2} \times 10^{3}$ \\
\hline \multirow{12}{*}{$\begin{array}{c}\text { Minutes } \\
0 \\
4.62 \\
6.56 \\
8.73 \\
10.50 \\
13.73 \\
17.50 \\
21.85 \\
24.81 \\
29.83 \\
34.69 \\
39.48 \\
45.53 \\
59.67\end{array}$} & ${ }^{\circ} \mathrm{S}$ & & \multirow{12}{*}{$\begin{array}{l}5.20 \\
3.87 \\
3.29 \\
2.99 \\
2.77 \\
2.30 \\
1.77 \\
1.40 \\
1.07 \\
0.82 \\
.54 \\
.38 \\
.24\end{array}$} & \\
\hline & +18.84 & & & - n \\
\hline & +18.51 & & & 36.3 \\
\hline & $\begin{array}{r}+18.49 \\
+18.50\end{array}$ & & & 27.3 \\
\hline & $\begin{array}{r}18.00 \\
+18.43\end{array}$ & $\cdots$ & & 24.8 \\
\hline & $\begin{array}{r}18.36 \\
+18.36\end{array}$ & ${ }^{-3}$ & & 26.4 \\
\hline & $\begin{array}{r}-18.50 \\
\end{array}$ & & & 25.6 \\
\hline & +18.51 & & & 27.7 \\
\hline & +18.81 & & & 26.7 \\
\hline & $\begin{array}{r}+19.05 \\
\end{array}$ & $\ldots$ & & 28.4 \\
\hline & +19.38 & 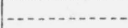 & & 28.9 \\
\hline & $\begin{array}{l}+19.82 \\
+20.85\end{array}$ & 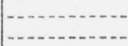 & & 29.5 \\
\hline \multirow{8}{*}{$\begin{array}{r}77.39 \\
90.36 \\
146.58 \\
185.30 \\
244.92 \\
295.12 \\
331.90 \\
24 \mathrm{hr} . \\
\text { A verage.-. }\end{array}$} & +22.13 & 3.28 & & \\
\hline & +23 & 3.45 & & \\
\hline & +26.17 & 3. 68 & .... & . \\
\hline & +27.48 & & & - non \\
\hline & +28.95 & 3. 70 & ........ & . \\
\hline & $\begin{array}{l}+29.67 \\
+30.07\end{array}$ & $\begin{array}{l}\text { 3. } 68 \\
\text { 3. } 72\end{array}$ & -and & - \\
\hline & +31.06 & . & & \\
\hline & - & 3. 59 & & 27.8 \\
\hline
\end{tabular}

TABLE 3.-Mutarotation of $\beta-d-2-$ desoxygalactose at $20^{\circ} \mathrm{C}$

\begin{tabular}{|c|c|c|c|c|}
\hline \multicolumn{5}{|c|}{$\begin{array}{l}4 \mathrm{~g} \text { in } 100 \mathrm{ml} \text { of water. } 1 \\
-16.7 \times 10^{-.0265 t+7.0 \times 10^{-.108 t}+27.1 .} \\
-37.3 \times 10^{-.0265 t}+15.6 \times 10^{-.105 t}+60.5 \text {. }\end{array}$} \\
\hline Time & $\begin{array}{l}\text { Observed } \\
\text { reading }\end{array}$ & $m_{1} \times 10^{3}$ & Deviation & $m_{2} \times 10^{3}$ \\
\hline Minutes & ${ }^{\circ} S$ & & & \\
\hline $\begin{array}{l}\text { 2. } 26 \\
\text { 3. } 21 \\
4.10 \\
4.89 \\
6.59 \\
7.99\end{array}$ & $\begin{array}{r}+15.03 \\
+15.13 \\
+15.12 \\
+15.30 \\
+16.25 \\
+16.82\end{array}$ & & $\begin{array}{l}\text { 2. } 51 \\
\text { 1. } 79 \\
\text { 1. } 05 \\
0.62 \\
.34\end{array}$ & $\begin{array}{r}155 \\
206 \\
231 \\
201 \\
\end{array}$ \\
\hline $\begin{array}{c}11.25 \\
13.49 \\
15.12 \\
20.92 \\
25.44 \\
29.68 \\
40.12 \\
50.09 \\
60.36 \\
20 \mathrm{hr} .\end{array}$ & $\begin{array}{l}+18.66 \\
+19.79 \\
+20.52 \\
+22.48 \\
+23.59 \\
+24.35 \\
+25.60 \\
+26.22 \\
+26.63 \\
+27.09\end{array}$ & $\begin{array}{l}26.3 \\
27.0 \\
27.2 \\
26.9 \\
26.8 \\
26.5 \\
26.1 \\
25.5 \\
25.8\end{array}$ & 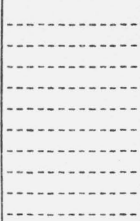 & (n) \\
\hline Average_. & - & 26.5 & $\ldots$ & 198 \\
\hline
\end{tabular}

1 Ordinary distilled water. 
The authors express their appreciation to Clement J. Rodden, of this Bureau, who made the microanalyses on the sugar.

\section{REFERENCES}

[1] H. S. Isbell and W. W. Pigman, J. Research NBS 18, 141 (1937) RP969.

[2] H. S. Isbell, J. Research NBS 18, 505 (1937) RP990.

[3] H. S. Isbell, J. Research NBS 19, 639 (1937) RP1052.

[4] H. S. Isbell, J. Research NBS 20, 97 (1938) RP1069.

[5] P. A. Levene and R. S. Tipson, J. Biol. Chem. 93, 644 (1931).

[6] W. W. Pigman and H. S. Isbell, J. Research NBS 19, 189 (1937) RP1021.

[7] M. Bergmann and H. Schotte, Ber. deut. chem. Ges. 54, 1570 (1921).

[8] H. S. Isbell and W. W. Pigman, J. Research NBS 20, 773 (1938) RP1104.

[9] G. M. Kline and S. F. Acree, BS J. Research 5, 1063 (1930) RP247.

[10] A. W. van der Haar, Monosaccharide und Aldehydsaüren, page 10 (Borntraeger Bros., Berlin, 1920).

[11] L. S. Munson and P. H. Walker, J. Am. Chem. Soc. 28, 663 (1906).

[12] F. M. Scales, J. Ind. Eng. Chem. 11, 747 (1919).

Washington, February 10, 1939. 